\title{
Influence of Scanning Speed on the Microhardness Property of Additive Manufactured Titanium Alloy
}

\author{
R. M. Mahamood \\ Department of Mechanical Engineering, University of Ilorin, Nigeria.
}

\begin{abstract}
Ti6A14V is an important aerospace alloy, and it is challenging processing this material through traditional manufacturing processes. Laser metal deposition, an additive manufacturing process offers lots of advantages for processing aerospace materials, the ability to increase buy-to-fly ratio by at least $80 \%$ amongst other things. An improved property is achievable through laser metal deposition. The Ti6A14V powder of particle size $150-200 \mu \mathrm{m}$ was deposited using a $4.0 \mathrm{~kW}$ Rofin Sinar Nd: YAG laser on $72 \times 72 \times 5 \mathrm{~mm}$ Ti6Al4V substrate. The powder was delivered using argon gas as a shield. The scanning speed was varied between 0.01 and $0.12 \mathrm{~m} / \mathrm{sec}$. The microstructures of the deposited layers were studied by optical microscope and the microhardness was also measured using the Vickers hardness tester. The properties of the deposited tracks were compared to that of the substrate. The microhardness was found to increase with increase in scanning speed.
\end{abstract}

KEYWORDS: Additive Manufacturing, Laser Metal Deposition, Microstructural Characterization, Scanning speed, Titanium Alloy

[Received August 31 2016; Revised December 13 2016; Accepted December 20 2016]

\section{INTRODUCTION}

Titanium and its alloys exhibit a very special combination of properties and corrosion resistance that have made them desirable for critical and demanding industrial uses. These include: aerospace, chemical and energy industry. Titanium alloys are unique lightweight, high strength alloys that are structurally efficient for critical, high-performance application such as aircraft for jet engine parts and airframe components (Richter et al. 2004). Despite these excellent properties, titanium alloys are difficult to machine which is responsible for the high cost of the material (Ezugwu and Wang, 1997; Machado and Wallbank, 1990; Yang and Liu, 1999). Alternative manufacturing method is desired to process titanium to reduce the cost of processing the material.

Laser Metal Deposition (LMD), an additive manufacturing technology, is an excellent alternative manufacturing method for processing titanium alloys for aerospace application. LMD is a layer by layer process that produces components directly from the computer aided design (CAD) data (Mahamood et al. 2014a; Scott et al. 2012). This is different from the traditional manufacturing process that produces components through series of material removal. The use of traditional manufacturing process to produce aerospace product wastes lots of materials because only ten percent of the material used are seen in the final product (Fink, 2009; Ploude, 2003). This is referred to as buy-to-fly ratio and it is one of the reasons for the high cost of aircraft.

LMD is a promising alternative manufacturing method because material utilization is on the high side as components are built through addition of material layer by layer. Also, LMD can be used to repair high valued component parts that

*Corresponding author’s e-mail address: mahamoodmr2009@gmail.com are prohibitive to be repaired and discarded in the past (Ploude, 2003; Bergan, 2012) and can be used to make part with functionally graded materials (Liu and Dupont, 2003). Lots of research has appeared in the literature in the last decades on the influence of processing parameters on the evolving properties of Ti6Al4V alloy using LMD (Wu et al. 2004; Griffith et al. 2000; Srivastava et al. 2001; Kelly and Kampe, 2004a; Brandl et al. 2011; Kelly and Kampe, 2004b; Gharbi et al. 2013; Schwender et al. 2001; Mok et al. 2008; Mahamood et al. 2014b and Kobryn et al. 2000). However, a lot still needs to be fully understood about the underlying physics of the LMD process, the effect of scanning speed on the evolving microstructure and property of the laser metal deposited titanium alloy.

For the aerospace industry to fully benefit from the exciting technology that promises to increase buy-to-fly ratio by at least $80 \%$, there is need to fully understand the role the scanning speed plays in the evolving properties of the titanium alloy. This is aimed at controlling the mechanical properties by controlling the scanning speed of the process. In this study, the effect of the scanning speed on the evolving microstructure and properties of Ti6Al4V, an important aerospace alloy, is studied through laser metal deposition of Ti6Al4V powder on Ti6Al4V substrate.

\section{MATERIALS AND EXPERIMENTAL PROCEDURE}

\section{A. Materials}

A commonly used aerospace alloy Ti6Al4V was used in this study. The dimension of the substrate used was $72 \times 72 \times$ $5 \mathrm{~mm} 3 \mathrm{Ti} 6 \mathrm{Al} 4 \mathrm{~V}$ plate. The Ti6Al4V powder of particle size of $150-200 \mu \mathrm{m}$ and of $99.6 \%$ purity was used, $99.6 \%$ pure

doi: http:/ /dx.doi.org/10.4314/njtd.v13i1.6 
Ti6Al4V is a high purity titanium alloy that is commercially available. The chemical compositions of the substrate material- Ti6Al4V, Ti6Al4V powder and $\mathrm{TiC}$ powder are presented in Tables 1, 2 and 3 respectively. The substrate was sandblasted and washed with acetone to remove grease and dirt as well as lso to reduce the laser reflection and aid absorption of the laser power during the deposition process.

Table 1: Chemical composition of Ti6Al4V substrate.

\begin{tabular}{lllllllll}
\hline Element & $\mathrm{Al}$ & $\mathrm{V}$ & $\mathrm{Fe}$ & $\mathrm{C}$ & $\mathrm{N}_{2}$ & $\mathrm{H}_{2}$ & $\mathrm{O}_{2}$ & $\mathrm{Ti}$ \\
\hline $\mathrm{W} \%$ & 6.42 & 3.91 & 0.19 & 0.008 & 0.006 & 0.004 & 0.155 & balance \\
\hline
\end{tabular}

Table 2: Chemical composition of the Ti6Al4V powder.

\begin{tabular}{lllllllll}
\hline Element & $\mathrm{Al}$ & $\mathrm{V}$ & $\mathrm{Fe}$ & $\mathrm{C}$ & $\mathrm{N}_{2}$ & $\mathrm{H}_{2}$ & $\mathrm{O}_{2}$ & $\mathrm{Ti}$ \\
\hline $\mathrm{W} \%$ & 6.20 & 3.90 & 0.18 & 0.008 & 0.005 & 0.005 & 0.150 & balance \\
\hline
\end{tabular}

Table 3: Chemical composition of the TiC powder.

\begin{tabular}{llllllll}
\hline Element & $\mathrm{C}$ & $\mathrm{O}_{2}$ & $\mathrm{~N}_{2}$ & $\mathrm{Fe}$ & $\mathrm{Al}$ & $\mathrm{Na}$ & $\mathrm{Ti}$ \\
\hline$\%$ & 19.5 & 0.28 & 0.4 & 0.045 & 0.03 & 0.026 & balance \\
\hline
\end{tabular}

\section{B. Experimental Method}

The deposition process was carried out using a $4.0 \mathrm{~kW} \mathrm{Nd}$ YAG laser that was fitted with coaxial nozzles for powder delivery. The aim of this study was to establish the influence of only the scanning speed on the properties on the deposit. Preliminary study was conducted to establish the process window which produced deposit that is fully dense and without porosity Mahamood et al. 2013). The minimum largest scanning speed and the values of all other processing parameters that are fixed in this study produce a pore free deposit. The laser spot size was maintained at $2 \mathrm{~mm}$ on the substrate at a distance of $195 \mathrm{~mm}$ focal length. The powder was delivered by argon gas at a flow rate of $21 / \mathrm{min}$.

The gas flow rate and all other fixed processing parameters in this study were selected based on preliminary studies that resulted in in fully dense deposit. In the laser deposition process, the laser beam created a melt pool on the surface of the substrate and the powder was delivered into the melt pool thereby creating a track of solid Ti6Al4V seen on the path of the laser beam. The schematic of the LMD process is shown in Figure 1 (a). The experimental set up consists of a kuka robot with the Nd-YAG laser and the powder nozzle collocated with the laser as shown in Figure 1 (b). The laser power was maintained at $3 \mathrm{~kW}$ and the powder mass flow rate at $2.88 \mathrm{~g} / \mathrm{min}$. The scanning speed was varied between 0.01 and $0.12 \mathrm{~m} / \mathrm{sec}$. The processing parameter is presented in Table 4.

After the deposition process, the samples were cut and laterally sectioned. The cut samples were metallurgically
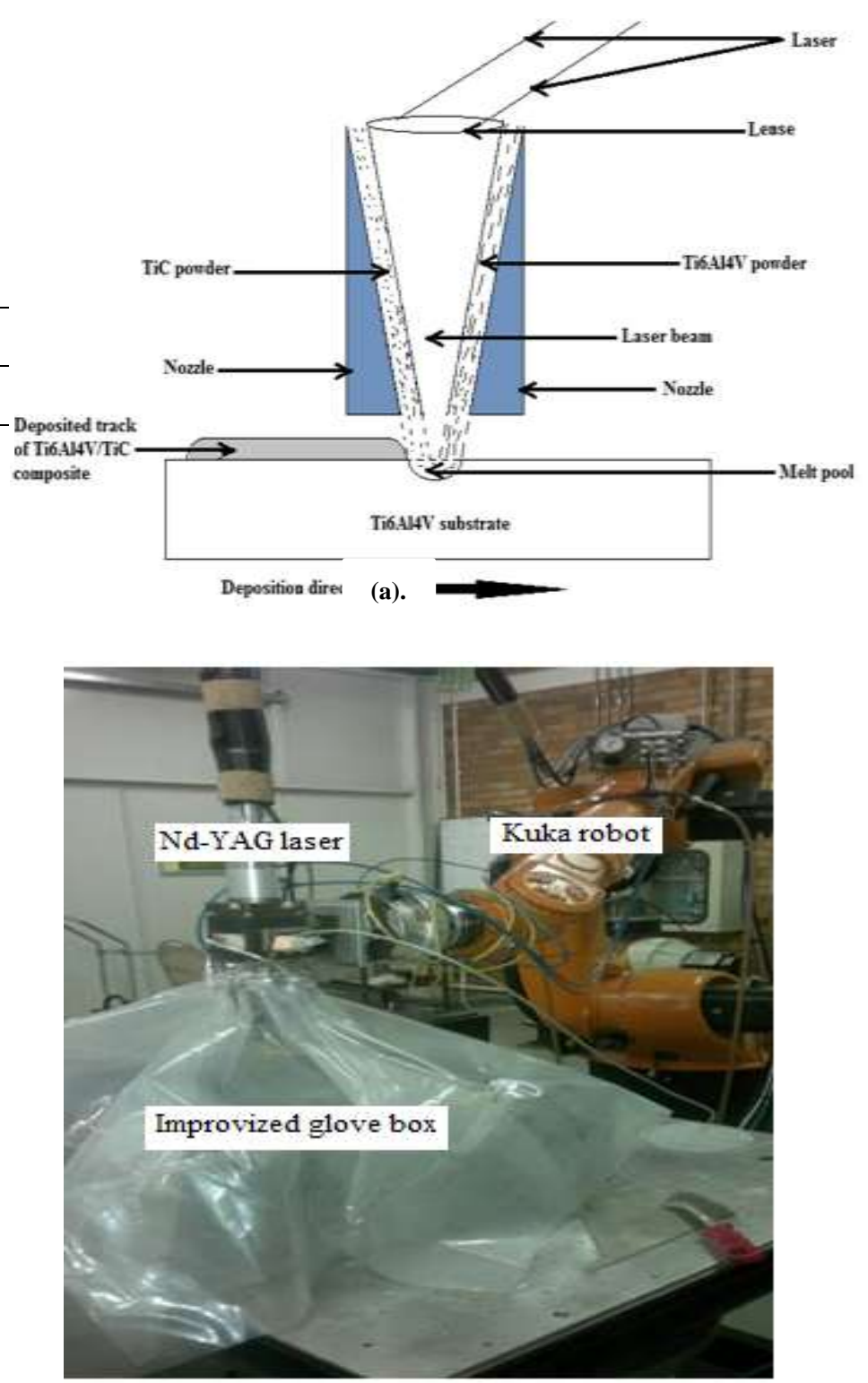

(b)

Figure 1. (a) Schematic of the LMD process (Mahamood et al. 2013) (b) Pictorial diagram of the experimental set-up.

prepared for microstructural observation. The cut samples were mounted in hot resin ground and polished according to the American Society for Testing and Materials (ASTM) standard of metallurgical preparation of titanium and its alloys (ASTM E3-11, 2011a). The microhardness was carried out on the polished samples using Metkon Vickers hardness tester with a load of $500 \mathrm{~g}$ and a dwell time of 15 seconds. The space between indentations is $15 \mu \mathrm{m}$ according to the ASTM standard for hardness measurement (ASTM E384, 2011b). Samples for the microstructural characterization were etched with Kroll reagent to reveal the microstructure. 
Table 4: Processing parameters.

\begin{tabular}{lllll}
\hline $\begin{array}{l}\text { Sample } \\
\text { Designation }\end{array}$ & $\begin{array}{l}\text { Laser } \\
\text { Power }(\mathbf{k W})\end{array}$ & $\begin{array}{l}\text { Scanning } \\
\text { Speed } \\
(\mathbf{m} / \mathbf{s e c})\end{array}$ & $\begin{array}{l}\text { Powder } \\
\text { Flow Rate } \\
(\mathbf{g} / \mathbf{m i n})\end{array}$ & $\begin{array}{l}\text { Gas Flow } \\
\text { Rate } \\
(\mathbf{l} / \mathbf{m i n})\end{array}$ \\
\hline $\mathrm{A}$ & 3 & 0.01 & 2.88 & 2 \\
$\mathrm{~B}$ & 3 & 0.02 & 2.88 & 2 \\
$\mathrm{C}$ & 3 & 0.03 & 2.88 & 2 \\
$\mathrm{D}$ & 3 & 0.04 & 2.88 & 2 \\
$\mathrm{E}$ & 3 & 0.06 & 2.88 & 2 \\
$\mathrm{~F}$ & 3 & 0.07 & 2.88 & 2 \\
$\mathrm{G}$ & 3 & 0.08 & 2.88 & 2 \\
$\mathrm{H}$ & 3 & 0.09 & 2.88 & 2 \\
$\mathrm{I}$ & 3 & 0.10 & 2.88 & 2 \\
$\mathrm{~J}$ & 3 & 0.11 & 2.88 & 2 \\
$\mathrm{~K}$ & 3 & 0.12 & 2.88 & 2 \\
\hline
\end{tabular}

\section{RESULTS AND DISCUSSION}

The micrographs of the Ti6Al4V substrate and the Ti6Al4Vpowder used are shown in Figure 2 ( $a$ and $b$ ). The microstructure of the Ti6Al4V substrate is made up of alpha and beta grains structures. The alpha grains (brighter grains) are in the matrix of the beta grains (darker grains) as shown in Figure 2 (a). This is typical of a Ti6Al4V alloy because of the alpha and beta stabilizing elements in the alloy. The powder is a spherically shaped gas atomized powder.

Spherically shaped powders are more favoured in the laser material processing because they absorb more laser energy and promote the transmission of the laser beam through the powder (Schade et al. 2014).

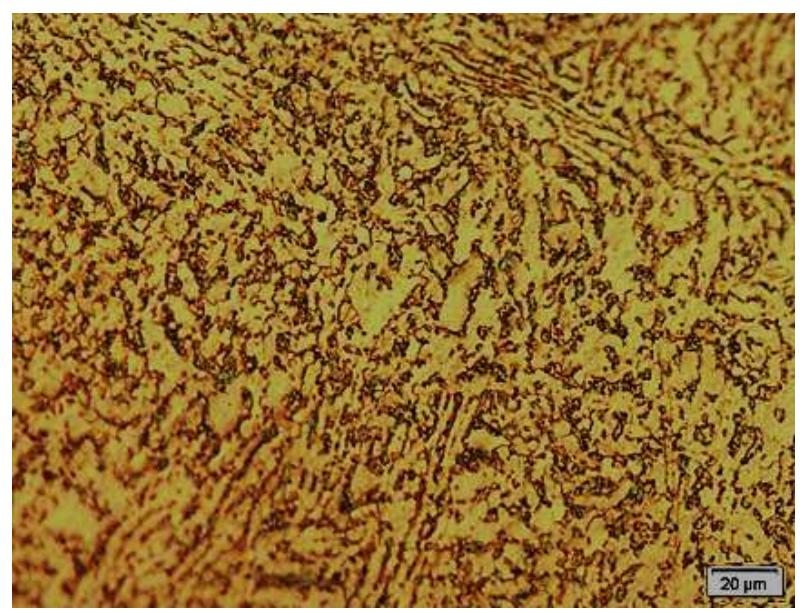

(a)

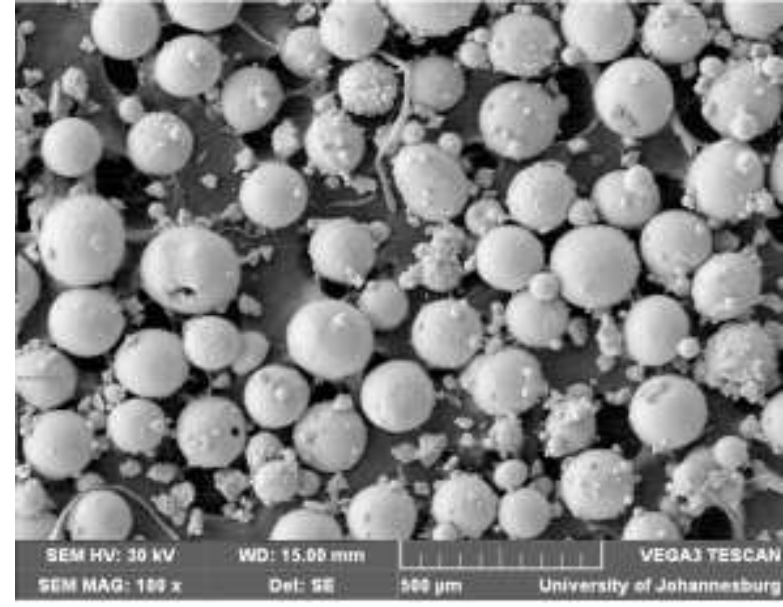

(b)

Figure 2. Micrograph of Ti6Al4V (a) substrate (b) powder.

The microstructure of the deposited samples showed that the deposition is porous free and fully dense. This can be attributed to the choice of other fixed process parameters employed, that is, the laser power, powder flow rate and gas flow rate based on preliminary study. The graph of the average microhardness against the scanning speed is shown in Figure 3 and the microstructures of the clad zone of samples at different scanning speeds are shown in Figure 4. The microhardness is seen to increase with increase in scanning speed. The reason for this behaviour can be attributed to the fact that, the laser material interaction time at lower scanning speed is longer than at higher scanning speed The longer the laser material interaction time, the larger the melt pool and the longer it takes to solidify (Kobryn, 2000; Mahamood et al. 2013).

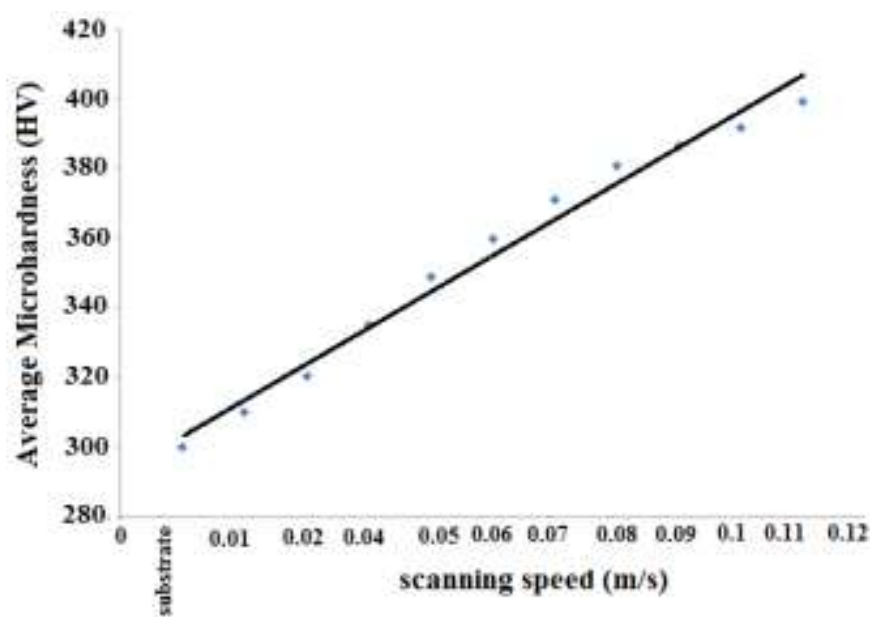

Figure 3. Graph of microhardness versus the scanning speed. 
The slower solidification at lower scanning speed promotes the formation of the Widmanstatten alpha in large proportion as seen in Figure 4 (a). Widmanstatten alpha are soft which is responsible for the low microhardness value at that low scanning speed.

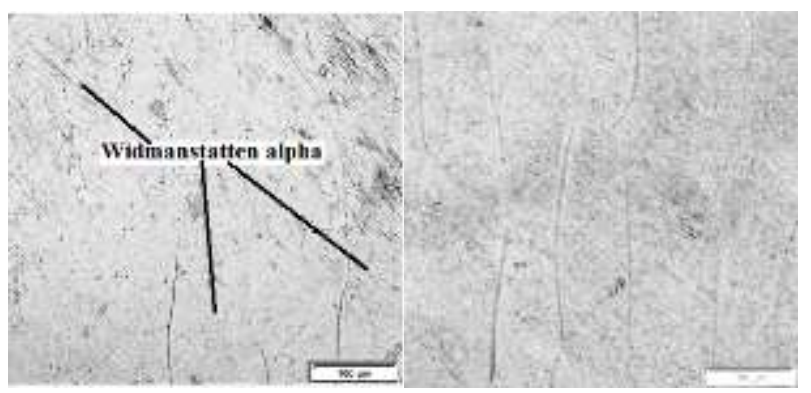

(a).

(b).

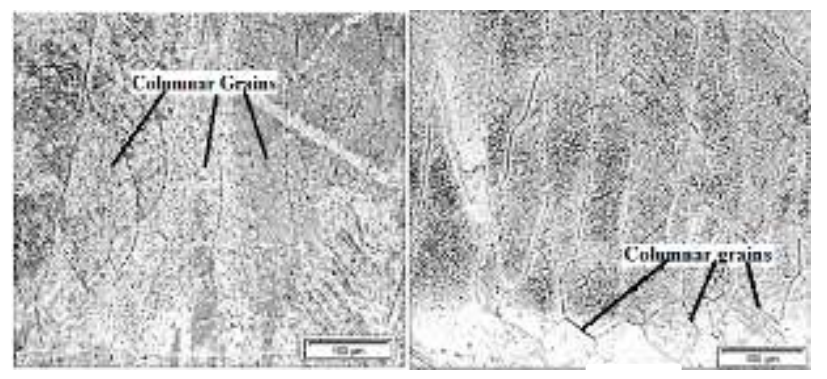

(c).

(d).

Figure 4. Micrograph of sample at varying scanning speeds (a) $0.01 \mathrm{~m} / \mathrm{s}$ (b) $0.03 \mathrm{~m} / \mathrm{s}$ (c) $0.06 \mathrm{~m} / \mathrm{s}$ (d) 0.12 .

At higher scanning speeds, the laser material interaction time reduces resulting in smaller melt pool that solidifies more quickly. The rapid solidification at higher scanning speed promotes the formation of martensitic alpha grains which are hard. It can be seen in Figures 4 (b), 4 (c), and 4 (d) that the proportion of the martensitic alpha in the microstructure increases as the scanning speed was increased. This is the reason why the microhardness values increased as the scanning speed was increased. Also, the columnar grain as indicated on the diagram in Figure $4 \mathrm{c}$ decreases in width as the scanning speed was increased. The reason for this is that, during the laser metal deposition process, the melt pool that is created on the surface of the substrate transferred heat from the melt pool to the remaining part of the substrate. The heat gained by the grains that are closer to the melt pool causes the grain growth that resulted in the formation of globular grains shown in Figure 4d.

The columnar grains grow epitaxially on the globular grains. At low scanning speed, the melt pool that is produced is lower than those produced at lower scanning speed, the grain growth are limited and hence large number of globular grains. At low scanning speed, the melt pool formed is larger and there is enough time for grain growth, giving rise to larger and fewer number of globular grains. Since the columnar grains grow epitaxially on the globular grains, hence the larger width of grains at lower scanning speeds.
The slimmer width of the columnar grains at higher scanning speed is also responsible for the higher microhardness of the samples at high scanning speed. This result is consistence with the literature (Wu et al. 2004; Brandl et al. 2011; Kobryn et al. 2000). The substrate has the lowest hardness value and all the samples have higher microhardness values than the substrate. This can be confirmed by the martensite seen in all the samples as seen in Figure 4 because of the rapid cooling rate that is associated with the LMD process. Although, the quantity of the martensitic alpha is found to decreases as the scanning speed was decreased. It is also seen that as the scanning speed increases, the martensite laths, $\alpha^{\prime}$, are decreasing in thickness, which is indicative of the increasing cooling rate.

\section{CONCLUSION}

This study showed that an improved property is achievable through the LMD process and control of property can also be achieved using varying scanning speed. Martensite, $\alpha$, are produced in the deposited layer in all the samples because of the rapid cooling taken place in the LMD process. Widmanstatten $\alpha$ are seen in in large proportion at low scanning speed and as the scanning speed was increased, the globular grains width continued to reduce and hence resulted in higher microhardness. It can be concluded that the hardness increases as the scanning speed increases and by controlling only the scanning speed, the property of the laser deposited Ti6Al4V can easily be controlled.

\section{REFERENCES}

ASTM E3-11 (2011a). Standard Guide for Preparation of Metallographic Specimens, ASTM international Book of Standards, 03(01).

ASTM E384 - 11e1 (2011b). Standard Test Method for Knoop and Vickers Hardness of Materials, ASTM International Book of Standards, 03 (01).

Bergan P. (2012). Implementation of Laser Repair Processes for Navy Aluminum Components, Proceeding of Diminishing Manufacturing Sources and Material Shortages Conference (DMSMS), available at: http://smaplab.ri.uah.edu/Smaptest/Conferences/dmsms2K/pa pers/decamp.pdf, accessed on 27th March, 2012.

Brandl, E.; F. Palm, V. Michailov, B. Viehweger and C. Leyens (2011). Mechanical Properties of Additive Manufactured Titanium (Ti-6Al-4V) Blocks Deposited by A Solid-State Laser and Wire. Materials \& Design, 32(10): 46654675.

Ezugwu, E.O. and Wang, Z.M. (1997). Titanium Alloys and Their Machinability A Review, Journal of Materials Processing and Technology, 68 (1997) 262-274.

Fink, C.W. (2009). An Overview of Additive Manufacturing. Part II, AMMTIAC Quarterly. 4(3): 7 -10.

Gharbi, M.; P. Peyre, C. Gorny, M. Carin, S. Morville, P. Le Masson and R. Fabbro, (2013). Influence of Various Process Conditions on Surface Finishes Induced by the Direct Metal Deposition Laser Technique on a Ti-6Al-4V Alloy. Journal of materials processing technology, 213(5): 791-800. 
Griffith, M. L.; M. T. Ensz, J. D. Puskar, C. V. Robino, J. A. Brooks, J. A. Philliber, J. E. Smugeresky and W. H. Hofmeister (2000). Understanding the microstructure and properties of components fabricated by laser engineered net shaping (LENS). In MRS proceedings. Cambridge University Press.

Kelly, S. M., and Kampe, S. L. (2004a). Microstructural Evolution in Laser-Deposited Multilayer Ti-6Al-4V Builds: Part I. Microstructural Characterization. Metallurgical and Materials Transactions A, 35(6): 1861-1867.

Kelly, S. M., and Kampe, S. L. (2004b). Microstructural Evolution in Laser-Deposited Multilayer Ti-6Al-4V Builds: Part II. Thermal Modeling. Metallurgical and Materials Transactions A, 35(6): 1869-1879.

Kobryn, P. A.; E. H. Moore and S. L. Semiatin (2000). The Effect of Laser Power and Traverse Speed on Microstructure, Porosity, and Build Height in Laser-Deposited Ti-6Al-4V. In: Scripta Materialia, 43: 299-305.

Liu, W. and DuPont, J. N. (2003). Fabrication of Functionally Graded TiC/Ti Composite by Laser Engineered Net Shaping. Scripta Materialia, 48(9): 1337-1342.

Machado, A.R. and Wallbank, J. (1990). Machining of Titanium and its Alloys A Review, Proceedings of the Institute of Mechanical Engineers Part B: Journal of Engineering Manufacture, 204: 53-60.

Mahamood, R. M.; E. T. Akinlabi, R. M., Shukla, M. and S. Pityana (2013). Scanning Velocity Influence on Microstructure, Microhardness and Wear Resistance Performance on Laser Deposited Ti6Al4V/TiC Composite. Materials and Design, 50: 656-666.

Mahamood, R. M.; E. T. Akinlabi, R. M., Shukla, M. and S. Pityana (2014a). Evolutionary Additive Manufacturing: An Overview. Lasers in Engineering, 27: 161178.

Mahamood, R. M.; E. T. Akinlabi, R. M., Shukla, M. and S. Pityana (2014b). Characterizing the Effect of Processing Parameters on the Porosity Properties of Laser Deposited Titanium Alloy, International Multi-conference of Engineering and Computer Science (IMECS 2014), Hong Kong, 3: 904-908.
Mok, S. H.; G. Bi, J. Folkes, and I. Pashby (2008). Deposition of Ti-6Al-4V using a High Power Diode Laser and Wire, Part I: Investigation on the Process Characteristics. Surface and Coatings Technology, 202(16): 3933-3939.

Ploude R. (2003). Laser-Based Repair System Reclaims High Value Military Components, NATO RTO-MP-AVT109, RTO-AVT Specialists Meeting -The Control and Reduction of Wear in Military Platforms, 2003.

Richter, E.; K. H. Orban and S. Nowotny (2004). Laser Cladding of the Titanium Alloy Ti6242 to Restore Damaged Blades. Proceedings of 23rd International Congress on Applications of Lasers and Electro-Optics, (ICALEO),San Francisco, CA, USA, 1:1-10.

Schade, C. T.; T. F. Murphy and C. Walton (2014). Development Of Atomized Powders for Additive Manufacturing, Powder Metallurgy Word Congress, Accessed on 2nd July 2014 available at http://www.gkn.com/hoeganaes/media/Tech\%20Library/Scha de-Atomized $\% 20$ Powders $\% 20$ for $\%$ 20Additive\%20Manufacturing\%20\%281\%29.pdf

Schwendner, K. I.; R. Banerjee, P. C. Collins, C. A. Brice, and H. L. Fraser (2001). Direct Laser Deposition of Alloys from Elemental Powder Blends. Scripta Materialia, 45(10), 1123-1129.

Scott, J.; N. Gupta, C. Wember, S. Newsom, T. Wohlers and T. Caffrey (2012). Additive manufacturing: status and opportunities, Science and Technology Policy Institute, Available from: https://www.ida.org/stpi/occasionalpapers/papers/A M3D_33012_Final.pdf (Accessed on 11 August 2016).

Srivastava, D.; I. T. H. Chang and M. H. Loretto (2001). The Effect of Process Parameters and Heat Treatment on the Microstructure of Direct Laser Fabricated TiAl Alloy Samples. Intermetallic, 9(12): 1003-1013.

Wu, X.; J. Liang, J. Mei, C. Mitchell, P. S. Goodwin and W. Voice (2004). Microstructures of Laser-Deposited Ti6Al-4V. Materials \& design, 25(2): 137-144.

Yang, X. and Liu, C. R. (1999). Machining Titanium and its Alloys, Machining Science and Technology 3 (1): 107139. 